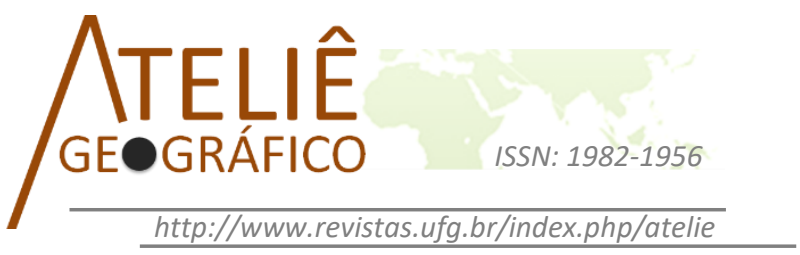

\section{O Brasil no mercado mundial de carne bovina: análise da competitividade da produção e da logística de exportação brasileira}

\author{
Brazil in the global marketplace for beef: analysis of the \\ competitiveness of Brazilian production and exportation \\ logistics
}
Brasil en el mercado mundial de carne de vacuno: análisis de la competitividad de la producción y de la logística de exportación brasileña

Onofre Aurélio Neto

Secretaria Municipal de Educação de Goiânia

opan.neto@yahoo.com.br

\begin{abstract}
Resumo
$\mathrm{O}$ artigo analisa a participação do Brasil no mercado mundial de carne bovina, atentando-se para a competitividade do país em relação à produção e exportação dessa commodity, entre o ano de 2000 e 2016, período de ascensão do país como um dos maiores exportadores de carne bovina. Avaliou-se a logística de exportação da carne a partir do território brasileiro, com a identificação dos modais, dos portos e mercados de destino. Apesar dos entraves existentes na logística de exportação e de enfrentar barreiras comerciais, conclui-se que o Brasil apresenta competitividade no comércio internacional de carne bovina, tendo ainda potencial para ampliar sua participação no mercado mundial.
\end{abstract}

Palavras-chave: Carne bovina, Competitividade, Exportação.

\begin{abstract}
The article analyses Brazil's role in the global marketplace for beef, considering the country's competitiveness in relation to the production and export of this commodity between 2000 and 2016, the period of the country's rise to become one of the largest exporters of beef. The logistics of meat exportation from Brazilian territory were evaluated, including the identification of modalities, ports and destination markets. Despite the bottlenecks that exist in exportation logistics and in the face of trade
\end{abstract}


barriers, it was found that Brazil is competitive in the international beef trade, with further potential to increase its participation in the global marketplace.

Keywords: Beef, Competitiveness, Exportation.

\section{Resumen}

El artículo analiza la participación de Brasil en el mercado mundial de la carne de vacuno, prestando atención a la competitividad del país en relación con la producción y la exportación de este producto, entre el año 2000 y 2016, período de crecimiento del país como uno de los mayores exportadores de carne de vacuno. Se evaluó la logística de exportación de la carne del territorio brasileño, con la identificación de los medios de transporte, puertos y mercados de destino. A pesar de los cuellos de botella existentes en la logística de exportación y de las barreras comerciales, se ha corroborado que Brasil tiene competitividad en el comercio internacional de carne, teniendo aún el potencial de aumentar su participación en el mercado mundial.

Palabras clave: Carne de vacuno, Competitividad, Exportación.

\section{Introdução}

Os estudos sobre o comércio internacional de produtos agropecuários são muito relevantes para o Brasil, visto que tais mercadorias apresentam participação significativa nas exportações do país, contribuindo para a entrada de divisas e comercialização do excedente que não é consumindo pela população interna. Em 2016, as remessas de produtos do setor agropecuário representaram $48 \%$ das divisas de exportação do país, as quais totalizaram US\$ 185,2 bilhões (BRASIL, 2016).

Como discutem Mata e Freitas (2006), a exportação de produtos agropecuários brasileiros é afetada por diversos fatores, entre os quais estão as vantagens comparativas e a competitividade, baseadas na capacidade produtiva de um determinado local frente aos seus concorrentes. A competitividade no comércio internacional envolve o volume de produção, oferta, custo de produção, qualidade do produto e logística de exportação, questões abordadas neste artigo, em relação ao setor da carne bovina.

$\mathrm{Na}$ análise da pauta exportadora, em 2016, somente a carne bovina contribuiu com 5,51 bilhões de dólares, correspondendo a 3\% do total (BRASIL, 2016). As exportações do setor frigorífico contribuem para um superávit na balança comercial do país, funcionando como um arrecadador de moeda estrangeira, mesmo com a existência de barreiras comerciais e operacionais que dificultam o processo de exportação de carnes para mercados estrangeiros. Desta maneira, torna-se relevante a avaliação do papel que o Brasil desempenha no comércio internacional de carne bovina, bem como verificar a evolução da competitividade deste setor relevante do agronegócio brasileiro.

Deste modo, o objetivo do trabalho é analisar o comércio internacional de carne bovina, de forma a avaliar a competitividade da produção e exportação brasileira 
para mercados externos. Para tanto, identificamos os países que foram os principais produtores e exportadores de carne bovina entre o ano de 2000 e 2016, verificamos os custos de produção do Brasil em relação aos seus principais concorrentes, com base no sistema produtivo, seguindo para um estudo comparativo do papel desempenhado pelos players da carne bovina no mercado mundial, ou seja, dos maiores exportadores dessa commodity. Adentramos na logística de exportação brasileira, ao constatar a concentração das exportações de carnes em apenas alguns portos como um gargalo a ser superado, a fim de fortalecer a competitividade brasileira e a sua atuação no mercado mundial.

A expressão "mercado mundial", como explica Marx (2008), refere-se ao comércio realizado entre distintas sociedades, envolvendo um grande número de países, com a expansão do modo de produção capitalista e das trocas comerciais, em escala cada vez mais ampliada de circulação. Por isso, o autor afirma que ocorre uma verdadeira competição entre as nações pelo mercado mundial. Partindo da compreensão de que os países apresentam disparidades e que competem entre si, Santos (1994, p. 31) afirma que "o espaço se globaliza, mas não é mundial como um todo, senão como metáfora". Por isso, a expressão "mercado mundial" não significa uma verdadeira homogeneização dos espaços, dos mercados e das coisas; mas uma inter-relação complexa entre diversos países, cujo objetivo principal é o comércio internacional.

\section{Procedimentos metodológicos}

Este trabalho pautou-se em tratamento de dados secundários e mapeamento de algumas variáveis selecionadas, com o objetivo de revelar suas formas de espacialização. Avergou-se as vantagens de produzir carne bovina no Brasil, em relação a outros países que se destacam mundialmente, segundo os dados de produção e oferta do Departamento de Agricultura dos Estados Unidos (USDA). Para mensurar a produção de carne bovina no território brasileiro foram utilizados dados da Pesquisa Trimestral de Abate dos Frigoríficos (2016) e da Pesquisa Pecuária Municipal (2015), disponibilizadas pelo Instituto Brasileiro de Geografia e Estatística (IBGE).

Aprofundou-se no estudo das exportações brasileiras, identificando os principais estados exportadores e os modais utilizados no processo de exportação, a partir de dados do Sistema de Análise das Informações de Comércio Exterior (ALICE WEB), vinculado ao Ministério do Desenvolvimento, Indústria e Comércio Exterior (MDIC). Além disso, empregamos os dados disponibilizados pela Associação Brasileira das Indústrias Exportadoras de Carnes (ABIEC), com o intuito de identificar a localização dos frigoríficos exportadores, os principais portos e os mercados estrangeiros que compram a carne bovina brasileira, por tipo de produto, volume e participação no valor das exportações. 


\section{A produção de carne bovina no território brasileiro}

Em 2016, o segundo maior rebanho bovino do mundo encontrava-se no território brasileiro (219 milhões de cabeças), correspondendo a $22,1 \%$ do plantel mundial. O primeiro lugar pertencia à Índia, com um rebanho de 302 milhões de cabeças de gado (USDA, 2016). Tal efetivo de animais permitiu ao Brasil ocupar a segunda colocação na produção mundial de carne vermelha. Além disso, como consta no relatório da OECD-FAO (2015), os investimentos em pesquisa agrícola nas últimas décadas fizeram com que o Brasil obtivesse melhores tecnologias para os produtores e as agroindústrias do setor pecuário, resultando em um expressivo aumento da produtividade.

Na Tabela 1, as estatísticas da produção mundial de carne de gado indicam que o Brasil aumentou sua produção em $31,8 \%$, entre 2000 e 2005 , tendo ainda um aumento de $6,1 \%$, entre 2005 e 2010, alcançando o volume de 9,11 milhões de toneladas em 2010. Já em 2016, a produção de carne de gado no país foi de 9,28 milhões de toneladas de equivalente carcaça (TEC), participando em 15,3\% do volume mundial. Apesar de ser uma participação significativa, observa-se uma retração de $1,5 \%$ na produção brasileira em relação ao ano de 2015 , o que se justifica pela diminuição temporária do consumo dessa commodity no mercado doméstico.

Tabela 01. Principais países produtores de carne de gado, por mil toneladas (20002016)

\begin{tabular}{|c|c|c|c|c|c|}
\hline Países & 2000 & 2005 & 2010 & 2015 & 2016 \\
\hline Estados Unidos & 12.298 & 11.318 & 12.046 & 10.817 & 11.389 \\
\hline Brasil & 6.520 & 8.592 & 9.115 & 9.425 & 9.284 \\
\hline União Europeia & 8.325 & 8.136 & 8.101 & 7.691 & 7.850 \\
\hline China & 5.131 & 5.681 & 6.531 & 6.700 & 6.900 \\
\hline Índia & 1.525 & 2.225 & 3.125 & 4.100 & 4.250 \\
\hline Argentina & 2.880 & 3.200 & 2.620 & 2.720 & 2.600 \\
\hline Austrália & 2.053 & 2.090 & 2.129 & 2.547 & 2.075 \\
\hline México & 1.900 & 1.725 & 1.745 & 1.850 & 1.880 \\
\hline Paquistão & 886 & 1.004 & 1.485 & 1.710 & 1.750 \\
\hline Rússia & 1.595 & 1.520 & 1.435 & 1.355 & 1.340 \\
\hline Outros países & 9.918 & 10.632 & 11.128 & 11.107 & 11.168 \\
\hline TOTAL* & 53.031 & 56.123 & 59.460 & 60.022 & 60.486 \\
\hline
\end{tabular}

*. O total refere-se à soma da produção dos países que fazem parte do banco de dados do USDA. Fonte: USDA (2016).

Os Estados Unidos foram os maiores produtores mundial de carne bovina ao longo do período analisado, com um volume de 11,38 milhões de toneladas em 2016, o 
equivalente a $18,8 \%$ da produção mundial; apesar de possuírem um rebanho bovino de 92 milhões de cabeças naquele ano, ou seja, menor que o plantel brasileiro. Conforme Olivo (2008), o destaque dos EUA apregoa-se à sua avançada tecnologia de produção, o que permite uma maior produção de arrobas em suas fazendas e alto aproveitamento das carcaças nas unidades processadoras.

Adentrando na produção brasileira de carne bovina, observa-se que apesar de o mercado doméstico absorver a maior parte da produção (cerca de $80 \%$ ), de maneira que o consumo interno influencia diretamente na produção, o efetivo nacional sofre também influência da abertura de mercados externos para a entrada da carne brasileira. Entre 2000 e 2005, por exemplo, quando aconteceu a Encefalopatia Espongiforme Bovina ("mal da vaca louca") na Europa, repercutiu em uma maior aceitação de carne bovina produzida no território brasileiro por países estrangeiros, em substituição à produção europeia. Nesse período, notamos um acréscimo de $21,9 \%$ no plantel de bovino no Brasil, aumentando de 169,8 milhões para 207,1 milhões de cabeças (IBGE, 2015).

Os sucessivos aumentos no preço da carne que ocorreram nos últimos anos incentivaram o setor pecuarista a investir na expansão dos rebanhos, visando atender a demanda crescente por esse produto, tanto no mercado doméstico quanto externo. De acordo com os dados do IBGE (2015), o efetivo bovino no Brasil já era de 215,1 milhões de cabeças em 2015, o que indica um crescimento de 4\% em 10 anos; estando o gado mais concentrado na Região Centro-Oeste (33,8\% do total), seguido da Região Norte $(21,9 \%)$ e da Região Sudeste (18\%), como consta na Figura 01.

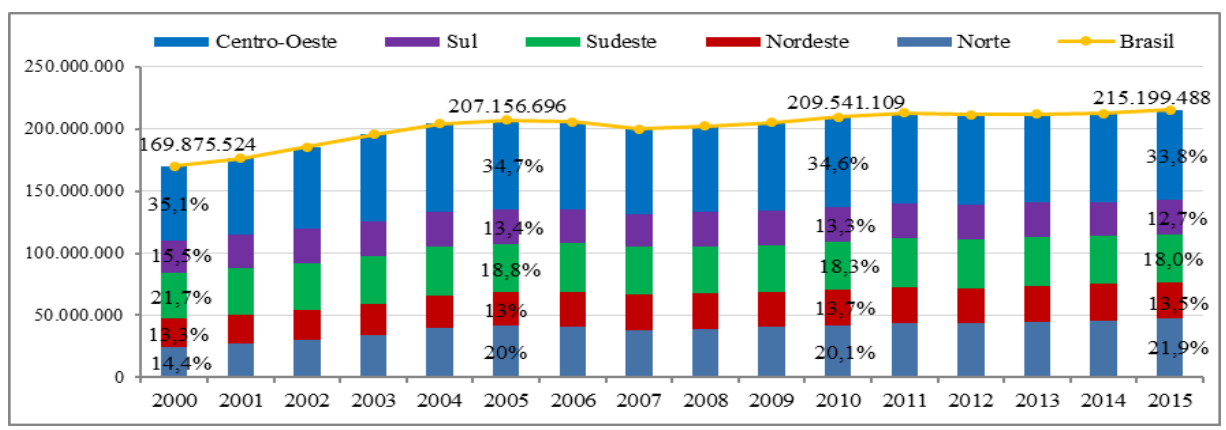

Figura 01. Evolução do efetivo bovino no Brasil, por regiões (2000-2015).

Fonte: IBGE (2015).

Ao longo do período analisado na Figura 1, a região brasileira que mais aumentou sua participação no plantel de bovinos foi a Região Norte, tendo um crescimento de 7,5 pontos percentuais entre o ano de 2000 e 2015. Os estados da região, principalmente o Pará, apresentam uma ampliação de suas áreas de pastagens, seguida do aumento do efetivo bovino que avança pela Amazônia, o que corrobora a tendência de direcionamento espacial da pecuária para o norte brasileiro, conforme já havia sido preconizado por Becker e Bernardes (1978), ainda na década de 1970. 
Acompanhado o aumento no efetivo de bovinos, o abate no país apresentou crescimento acentuado, desde o ano de 2000 até 2007, passando de 17 milhões de animais abatidos naquele ano para mais de 30 milhões, tendo o abate de vacas como o principal item para puxar o crescimento. Contudo, houve uma variação negativa no número de animais abatidos entre 2008 e 2011 (FIGURA 2). Essa queda esteve relacionada à crise econômica norte-americana de 2008, com repercussão na Europa nos anos seguintes; e aos obstáculos e restrições temporárias impostos por alguns países a carne oriunda do Brasil, com a divulgação de alguns casos de epizootias.

Nos últimos anos, observa-se um novo decréscimo no quadro de abate de bovinos, quando o número de animais abatidos no país reduziu de 34,4 milhões em 2013, para 29,6 milhões em 2016 (IBGE, 2016). A Figura 2 evidencia que o principal tipo de rebanho abatido no país é o boi $(56,1 \%)$, seguido do quantitativo de vacas (30\%). Ainda em 2016, a redução de $12,5 \%$ no total de abate, em relação ao ano de 2014, foi puxada pela diminuição no número de novilhos, novilhas e vacas abatidos, cujas reduções foram de $22,1 \%, 19,4 \%$ e $19,2 \%$, respectivamente.

Essa diminuição foi um reflexo, sobretudo, da contração da demanda interna; uma vez que por questões econômicas, nos anos de 2015 e 2016, a população brasileira substituiu parte da carne vermelha a ser consumida por carnes brancas, já que apresentam menores preços por quilo. Os dados do USDA (2016) indicam que o consumo doméstico de carne vermelha, no Brasil, caiu de 7,89 milhões de toneladas em 2014, para 7,49 milhões de toneladas em 2016, uma redução de 5\%. O setor pecuário brasileiro respondeu ao problema da diminuição da demanda com a redução do abate dos novilhos e novilhas, animais mais novos (variando de 18 a 24 meses), mantendo-os em pé. De tal modo, adiou o abate desses animais na expectativa de um novo aquecimento do mercado.

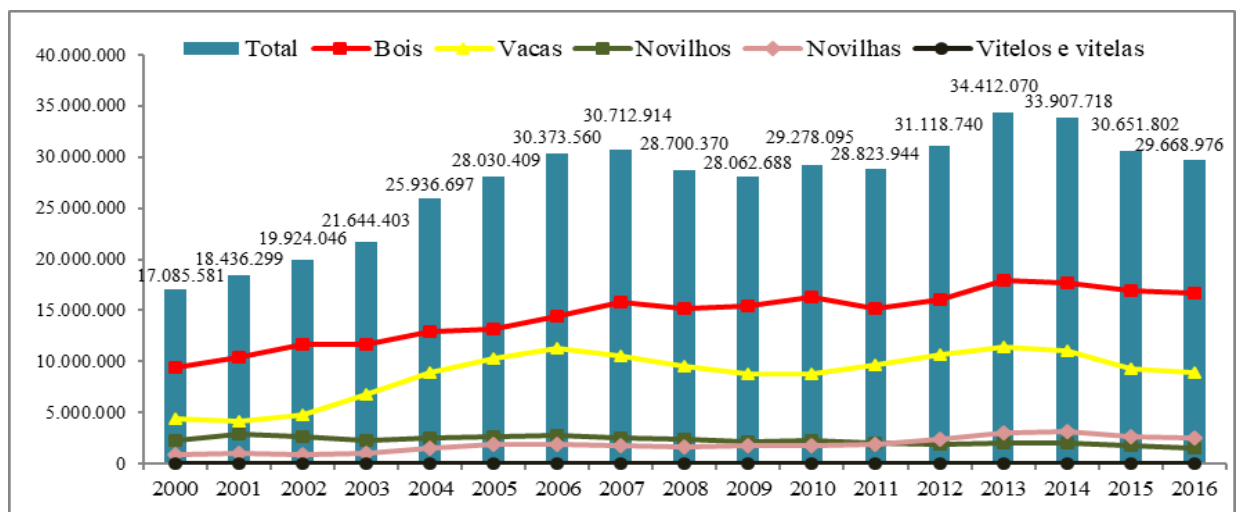

Figura 02. Evolução do abate de bovinos, por tipo de rebanho no Brasil (2000-2016) Fonte: IBGE (2016). 
Em 2016, participaram como informantes da Pesquisa Trimestral de Abate um total de 1.221 frigoríficos abatedouros de bovinos no país, sendo 200 estabelecimentos sob inspeção sanitária federal, 395 estaduais e 606 municipais (IBGE, 2016). Os frigoríficos sob inspeção sanitária federal, dispondo do Selo de Inspeção Federal (SIF), são habilitados para atuar em todo o mercado nacional ou mesmo enviar para mercados estrangeiros. Esses estabelecimentos foram responsáveis pelo abate de 21,9 milhões de bovinos em 2016, o que representou $74,1 \%$ do total de abate registrado no país e uma produção de 5.731.430.056 quilos de carne bovina (IBGE, 2016).

Independente do tipo de inspeção a que foram submetidos os estabelecimentos frigoríficos, os estados brasileiros que mais abateram cabeças de gado foram aqueles que compõem o chamado "Brasil Central Pecuário". Em 2016, o Mato Grosso liderava o ranking nacional, com o abate de 4.577.459 bovinos, seguido do Mato Grosso do Sul (3.292.279 cab.), Goiás (2.821.463 cab.) e São Paulo (2.792.350 cab.), como indica a Figura 3. Destaca-se que esses estados estavam entre os 10 maiores produtores de gado no país, sendo 29,3 milhões de reses em Mato Grosso, 21,8 milhões de cabeças em Goiás, 21,3 milhões em Mato Grosso do Sul, e um plantel de 10,4 milhões de bovinos em São Paulo (IBGE, 2015).

Percebe-se que o volume de animais abatidos, assim como a localização dos frigoríficos exportadores, estava relacionado à oferta de matéria-prima, ou seja, a existência de bovinos que atingissem o peso ideal de abate (entorno de $460 \mathrm{~kg}$ ). Visto que uma grande distância dos abatedouros em relação às fazendas de gado levaria a um demasiado tempo de transporte dos bovinos, resultando em maior custo com a logística que fica a cargo dos frigoríficos, possibilidade de perda de peso dos animais e redução no rendimento das carcaças.

Em 2016, o rendimento médio das carcaças de bovinos abatidos no país foi de 247,7 quilos/cabeça, considerando que o volume total de abate era de 29.668.976 cabeças e o peso total das carcaças havia sido de 7.350.297.393 kg (IBGE, 2016). Alguns estados brasileiros apresentaram um rendimento das carcaças acima da média nacional, destacando os valores registrados em São Paulo, com o maior rendimento médio (270,5 kg/cab.), seguido de Mato Grosso (265,2 kg/cab.) e Goiás (259,2 kg/cab.). Nesses estados, o maior peso dos bovinos engordados em sistema de confinamento favoreceu o maior rendimento das carcaças.

O Brasil é um país com vantagens comparativas para a produção de carnes, como discute Olivo (2008), com grandes dimensões de terras e condições climáticas favoráveis a diversos sistemas de produção capazes de converter a proteína vegetal em animal. A produção de carne bovina no território brasileiro é realizada majoritariamente em sistema de pastagens (90\%), sendo que na fase final do ciclo produtivo o gado pode ser conduzido para o confinamento, representado este sistema intensivo $10 \%$ do gado terminado para abate no país (ABIEC, 2015).

Segundo dados do relatório anual de 2015 da ABIEC, existiam mais de 167 milhões de hectares de pastos no país. Contudo, sabe-se que parte das áreas de 
pastagens encontra-se subutilizada ou em estado de degradação; o que indica uma capacidade de expansão do rebanho, a partir do melhor uso das áreas de pastoreio já existentes e aumento da taxa de lotação, a qual se encontra em torno de 1,23 cabeças por hectare (ABIEC, 2015).

O elevado percentual de animais criados no sistema de produção "boi verde" (boi no pasto) contribui para que o Brasil tenha um dos menores custos de produção de carne bovina do mundo, visto que a alimentação do gado é constituída de pastagens, principalmente, enquanto que outros países precisam utilizar mais silagem/feno, grãos, concentrados, sais minerais e outros insumos na dieta dos ruminantes, o que aumenta o custo de produção no espaço rural.

De acordo com os levantamentos realizados pelo Agri Benchmark (2015), o Brasil apresenta um baixo custo de produção, tanto na fase de criação de bezerros quanto de engorda do gado. $\mathrm{O}$ custo de produção nas fazendas brasileiras de criação de gado estaria em torno de 200 dólares por 100 quilos de peso vivo, valor abaixo do praticado em países europeus (Alemanha, Espanha, França, Irlanda), nos Estados Unidos e México, por exemplo. O baixo custo no Brasil, em relação aos produtores estrangeiros, atribui-se ao fato do país possuir um custo menor nos fatores de produção: terra, pastagem e mão de obra (AGRI BENCHMARK, 2015).

O menor custo de produção do setor pecuário brasileiro contribui para que o país oferte a carne a um preço menor do que alguns concorrentes no mercado mundial, o que torna seu produto mais atrativo. No início de 2016, por exemplo, a arroba do boi gordo estava sendo comercializada no Brasil por 37,14 dólares; já nos Estados Unidos a cotação da arroba do boi era de US\$ 72,86; na Austrália o preço praticado foi de US\$ 66,60 por arroba; enquanto que no Uruguai a arroba do boi estava sendo vendida por 51,30 dólares, de acordo com as cotações da Scot Consultoria (2016).

Lucena e Souza (2011, p. 195) afirmam que o preço é uma variável relevante da capacidade de competição entre os fornecedores, sendo que a diferença entre o preço praticado no mercado internacional e o preço doméstico indica uma competitividade; de maneira que se considera competitivo o "país, setor ou indústria cujo preço de um produto se situa abaixo do verificado no mercado internacional", como é o caso da produção de carne bovina no Brasil.

A alimentação baseada em pastagem constitui uma vantagem também para os exportadores brasileiros de carne vermelha, visto que a complementação da dieta dos bovinos com ração de osso desencadeou, em outros países, a "doença da vaca louca". Portanto, ao possuir uma grande quantidade de pastagens, o Brasil apresenta uma vantagem comparativa neste fator de produção. Ao mesmo tempo, como indicam Ordoñez et al. (2007), as indústrias frigoríficas investiram tanto na tipificação das carnes para alcançar nichos de mercados variados, quanto na produtividade para adentrar em mercados internacionais com preços competitivos, adotando certificados de qualidade e de origem do produto. 


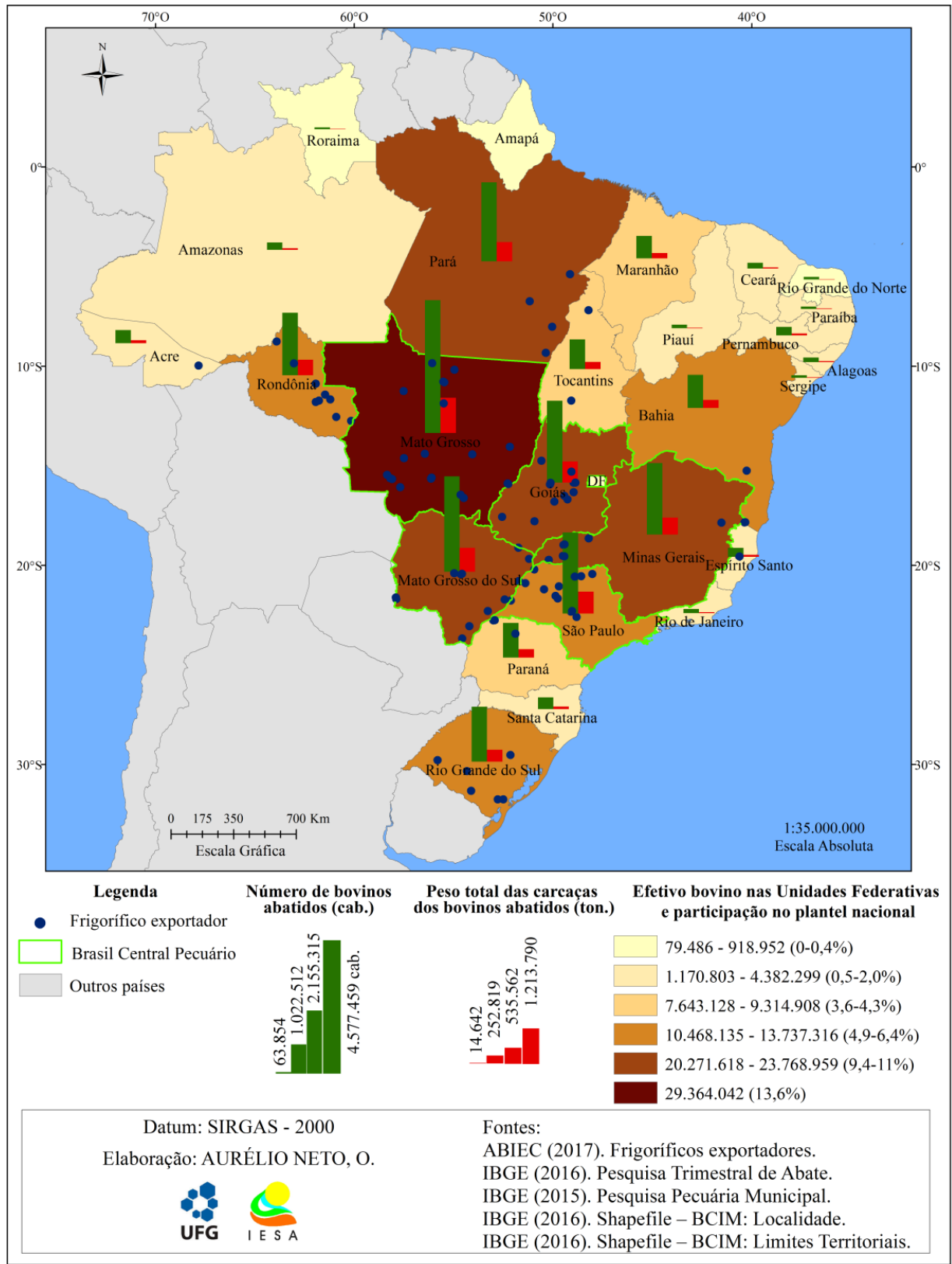

Figura 03. Efetivo bovino, abate e peso das carcaças nos estados brasileiros (2016) Fonte: ABIEC (2017); IBGE (2016 e 2015) 
No Brasil, as inovações tecnológicas que ocorrem no setor de carne são aplicadas para atenderem exigências dos mercados importadores de carnes e dos órgãos reguladores, a exemplo do Sistema Brasileiro de Identificação e Certificação de Origem Bovina e Bubalina (SISBOV). Implantado a partir de 2002, o seu propósito é o rastreamento das informações ao longo de toda a vida do animal para fornecer ao consumidor um produto livre de contaminantes e de melhor qualidade. Contudo, a sua adesão permanece obrigatória somente para as carnes destinadas ao mercado externo.

\section{Exportações de carne bovina e o mercado mundial}

Em nível mundial, os dados do USDA (2016) indicam que houve um crescimento na demanda de carne bovina entre o ano de 2000 e 2005, repercutindo em um aumento de $22 \%$ nas exportações, que passaram de 5,9 para 7,3 milhões de toneladas. Segundo Ordoñez et al. (2007), esse aumento está relacionado à ascensão da Rússia como o maior comprador de carne, passando a ser um dos mercados de maior relevância; e o estabelecimento de novos acordos comerciais para esse produto, impulsionados pelo surto da gripe aviária, o que provocou a redução temporária do consumo de carne avícola e o aumento do consumo de carne vermelha.

Aproveitando deste macro cenário, o Brasil ascendeu como o maior exportador de carne de gado em 2004, superando o volume de remessas dos EUA e da Austrália, ao destinar 1,61 milhões de toneladas de equivalente carcaça para o comércio exterior (Figura 04). A drástica redução nas exportações norte-americanas - caindo de 1,14 milhões de toneladas em 2013, para 209 mil no ano seguinte - atribui-se aos casos de animais diagnosticados com o "mal da vaca louca" em seu rebanho.

Por sua vez, a retração nas exportações de carne bovina da Argentina no ano de 2001, conforme Ordoñez et al. (2007), deve-se ao surto de febre aftosa que ocorreu no país em julho daquele ano, devido ao contrabando de animais provenientes do Paraguai. Segundo esses autores, tal fato foi agravado com a tentativa de ocultação da situação por parte das autoridades e serviços sanitários da Argentina. Os resultados desses acontecimentos foram: perda do status de país livre de aftosa; queda nas exportações argentinas de carne bovina, com o fechamento dos mercados externos até o ano de 2002; e alerta no mercado internacional, provocando o aumento das restrições ao comércio de carnes. As exportações argentinas retomaram o impulso em 2003, alcançando seu maior valor em 2005, quando foram exportados 754 mil toneladas de carne bovina do território argentino (USDA, 2016).

Entre 2004 e 2010, o Brasil foi líder mundial nas exportações de carne vermelha, com recorde em 2007, quando as remessas somaram mais de 2,1 milhões de toneladas. Ao longo de sete anos, o crescimento das exportações dessa commodity do Brasil foi de $348,6 \%$, entre o ano de 2000 e 2007. Tal crescimento deve-se a sanidade animal do rebanho, a capacidade de produção e aos novos acordos comerciais, o que 
possibilitou a exportação da carne proveniente do território brasileiro para mais de 150 países.

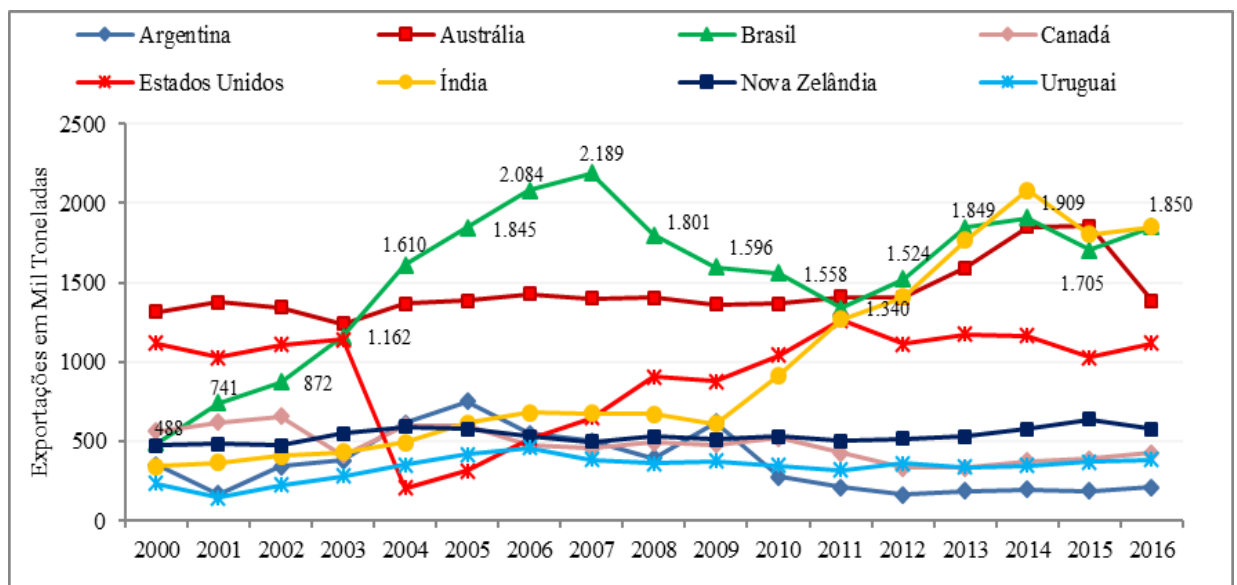

Figura 04. Exportações de carne de gado, por mil toneladas (2000-2016) Fonte: USDA (2016).

Todavia, o Brasil sofreu uma retração no volume exportado nos anos seguintes (2008-2011), em decorrência de problemas financeiros enfrentados pelos principais países importadores, o que levou a uma queda no comércio exterior de carne bovina. Além disso, a redução ocorrida em 2008 esteve relacionada aos embargos temporários de países estrangeiros ao produto brasileiro.

Destaca-se ainda, no período analisado, o crescimento nas exportações da Índia, passando de 344 mil toneladas no ano de 2000, para 1,41 milhões de toneladas em 2012 (USDA, 2016). O Brasil voltou a ocupar a primeira colocação geral nas exportações de carne vermelha em 2013, ao enviar 1,84 milhões de toneladas ao mercado externo. Apesar de apresentar um crescimento de 3,2\% no ano seguinte, a exportação brasileira foi novamente superada pela indiana (FIGURA 4).

A Índia registrou um volume de dois milhões de toneladas de carne vermelha exportada em 2014, o que correspondeu a 20,8\% das exportações daquela commodity no mundo. Como salienta Souza (2008), o alto volume de exportações desse país asiático está relacionado ao seu baixo custo de produção, o que é repassado ao preço final da carne, apesar de apresentar uma carne considerada de menor qualidade, tendo como principais mercados importadores o sudeste da Ásia e o Oriente Médio.

Em 2015, o primeiro lugar pertenceu à Austrália, um tradicional país exportador de carne vermelha que passou por dificuldades no setor por questão de secas e epizootias no rebanho em anos anteriores, mas que retomou o ritmo de produção naquele ano, quando exportou 1,85 milhões de toneladas de carne, ultrapassando as 
exportações da Índia e do Brasil. Já em 2016, o Brasil e a Índia voltaram a disputar pelo primeiro lugar nas exportações mundiais de carne vermelha (FIGURA 4). Em conjunto, esses três países representaram $53,9 \%$ das exportações mundiais de carne de gado e vitelo em 2016, o que indica uma alta concentração de mercado.

Com os incrementos nas exportações de carne nos últimos anos, esse gênero alimentício tem contribuído para a balança comercial brasileira, seja pelo maior volume exportado ou pelos acréscimos no valor da tonelada de carne praticado no comércio exterior. Em 2016, o montante arrecadado com as exportações de carne bovina foi de US\$ 5,51 bilhões (MDIC, 2016). Naquele ano, como consta na Tabela 2, somente o estado de São Paulo exportou mais de 371 mil toneladas de carne bovina, resultando em um montante de US\$1,59 bilhão, o que representou 28,9\% do total arrecadado com as exportações de carne bovina pelo país.

Tabela 02. Principais estados brasileiros exportadores de carne bovina, por valor e peso (2016)

\begin{tabular}{|l|c|c|c|c|c|c|}
\hline \multirow{2}{*}{ Estado } & \multicolumn{2}{|c|}{ Carne bovina in natura* } & \multicolumn{2}{c|}{ Outros tipos** } & \multicolumn{2}{c|}{ Total } \\
\cline { 2 - 7 } & US\$ FOB & Peso (kg) & US\$ FOB & Peso (kg) & US\$ FOB & Peso (kg) \\
\hline São Paulo & 1.038 .340 .481 & 251.525 .282 & 557.652 .581 & 119.987 .066 & 1.595 .993 .062 & 371.512 .348 \\
Mato Grosso & 890.460 .948 & 212.577 .884 & 55.104 .569 & 25.203 .185 & 945.565 .517 & 237.781 .069 \\
Goiás & 691.257 .144 & 165.452 .450 & 45.820 .062 & 19.597 .555 & 737.077 .206 & 185.050 .005 \\
Mato Grosso do Sul & 425.241 .737 & 103.560 .106 & 38.582 .319 & 16.999 .616 & 463.824 .056 & 120.559 .722 \\
Rondônia & 417.838 .105 & 113.808 .454 & 32.047 .804 & 13.299 .151 & 449.885 .909 & 127.107 .605 \\
Minas Gerais & 325.846 .552 & 80.394 .710 & 28.883 .940 & 11.959 .849 & 354.730 .492 & 92.354 .559 \\
\hline
\end{tabular}

*. Carnes de bovino, congeladas, frescas ou refrigeradas. **. Preparações alimentícias e conservas da espécie bovina, miudezas comestíveis, tripas e carnes de bovinos salgadas, secas ou defumadas.

Fonte: ALICE WEB (2016).

Dos frigoríficos localizados no Mato Grosso foram exportados mais de 237,7 mil toneladas de carne bovina, sendo 212,5 mil toneladas de carne in natura (congeladas, frescas ou refrigeradas); e 25,2 mil toneladas de outros produtos cárneos (ALICE WEB, 2016). As exportações a partir do território goiano somaram 185 mil toneladas de carne bovina, o que gerou uma receita de 737 milhões de dólares. Em Goiás, assim como em todos os principais estados brasileiros exportadores de carne bovina, predominava o envio de carne in natura para os mercados estrangeiros (TABELA 02). 
O incremento nas exportações brasileiras de carne está relacionado à expansão dos mercados importadores, com o estabelecimento de novos acordos comerciais, e ao aumento na demanda por parte de tradicionais consumidores, em parte, devido às inovações tecnológicas no campo e na indústria frigorífica que levaram a produção de carnes com maior controle de qualidade e garantia de procedência. Enquanto exportadores tradicionais enfrentavam problemas para controlar surtos de doenças em seus rebanhos, conforme Pardi et al. (2005), como foi o caso da Encefalopatia Espongiforme Bovina em países estrangeiros (Reino Unido, França, Portugal, Holanda, Suíça, Alemanha, Canadá, Estados Unidos etc.).

Essa situação exigiu um maior controle no comércio internacional de produtos da pecuária bovina, o que reforçou as barreiras sanitárias que já se aplicavam ao setor. De acordo com Neves et al. (2012), as empresas do setor frigorífico no Brasil estão atentas para as exigências do mercado internacional, com a implantação de medidas sanitárias que garantam uma melhor qualidade do produto. De fato, para inserir a carne bovina brasileira no mercado externo, os produtores estão se adaptando às exigências de países importadores, por exemplo, com a implantação do sistema de "rastreabilidade de bovinos", relacionado à informação da origem e qualidade do produto.

Apesar disso, a Operação "Carne Fraca", deflagrada pela Polícia Federal, no dia 17 de março de 2017, revelou problemas pontuais em alguns frigoríficos brasileiros, contestando a qualidade sanitária de alimentos cárneos de bovinos, suínos e aves, a qual foi construída ao longo de vários anos de pesquisas e investimentos no setor. As investigações da Operação Carne Fraca, em suma, constatou um esquema de propina para facilitar a comercialização de alimentos adulterados em 21 frigoríficos, envolvendo a participação de algumas pessoas ligadas ao Ministério da Agricultura, Pecuária e Abastecimento (MAPA).

$\mathrm{O}$ mercado mundial respondeu às notícias de adulteração de produtos alimentícios impondo suspensões temporárias aos frigoríficos investigados pela Polícia Federal, o que desencadeou a "crise da carne brasileira". Esse foi o caso da China, Hong Kong, União Europeia, Coreia do Sul e Chile, que anunciaram a suspensão temporária de carnes do território brasileiro dois dias após a operação (BORGES, 2017). Tal situação pode acarretar perda de credibilidade e de participação no comércio internacional, abrindo espaço para países concorrentes do Brasil nesse mercado, tais como Austrália e Argentina. De acordo com os dados da balança comercial semanal, logo na primeira semana depois da Operação Carne Fraca, os embarques de carne in natura do Brasil foram 19\% menores em relação à semana anterior (AGROIN, 2017).

No entanto, os Estados Unidos, entre outros países importadores, decidiram mantear à entrada de carne brasileira em seu território, visando conservar o comércio exterior e evitar possíveis retaliações, uma vez que reconheceram os problemas como pontuais e não generalizados. Esse voto de confiança na qualidade da carne brasileira, juntamente com as ações de autoridades do país - no sentido de apurar os casos, emitir informações técnicas e esclarecimentos aos mercados importadores -, levaram ao fim 
das suspensões e retomada das exportações; também teve um peso significativo à reabertura do mercado chinês, o que foi visto por outros países como um atestado da solidez e qualidade do sistema sanitário brasileiro (BORGES, 2017). Outra questão a ser enfrentada pelos exportadores de carne no Brasil refere-se aos obstáculos operacionais existentes na logística de exportação, como se discutirá no próximo tópico.

\section{A logística de exportação do território brasileiro}

Em relação às exportações de carnes, os principais modais utilizados são o transporte rodoviário e marítimo para alcançar mercados externos distantes. O modal rodoviário abrange praticamente todo o território brasileiro, sendo responsável pelo maior volume de movimento de cargas internamente. Conforme os dados da Secretaria de Comércio Exterior, em 2016, o modal rodoviário foi responsável pelas remessas de 75.976.515 quilos de carne bovina para mercados estrangeiros (5,5\%); enquanto que o modal aeroviário foi utilizado para exportar 1.284.240 quilos de carne bovina ou 0,1\%. De fato, a principal via utilizada nas exprotações dessa commodity foi a marítima, sendo esse modal o responsável pelo envio de 1.271.234.146 quilos de carne bovina, o que representou 92,1\% do volume exportado (ALICEWEB, 2016).

Assim, os portos litorâneos desempenham um papel relevante na logística de exportação de carne bovina, por estarem entre os principais pontos fixos da rede de logística no comércio exterior brasileiro, composta pelos frigoríficos, centros de distribuição e armazenamento, portos nacionais, navios de carga e portos estrangeiros. Por esses pontos fixos de circulação de mercadorias passam os fluxos materiais (carnes, grãos, minérios, produtos industrializados etc.), de maneira que se configuram como nós da rede logística internacional.

No Brasil, os principais portos utilizados nas exportações de carne bovina foram: o de Santos (SP), com o envio de 758.706 toneladas de carne bovina para o comércio exterior (54,2\% do volume exportado); o de São Francisco do Sul (SC), com $15,1 \%$ de participação nas exportações; o de Paranaguá (PR), com 9,0\% de participação; o de Itajaí (SC), com 6,5\%; o de Barcarena (PA), com 4,4\%; o de Dionísio Cerqueira (SC), com 3,8\%; o de Rio Grande (RS), com 3,5\%; e o de São Borja (RS), com 1,2\% de participação nas exportações (ABIEC, 2016).

A concentração das exportações de carne bovina nos portos da Região Sul e Sudeste evidencia os corredores de exportação dos estados brasileiros produtores de carne situados nas regiões Centro-Oeste, Sul e Sudeste. Como é o caso dos frigoríficos de Mato Grosso, por exemplo, estado do Centro-Oeste que se encontra integrado ao litoral pelo modal rodoviário e ferroviário. Sendo que as rodovias BR-364 e BR-163 estão entre as principais vias de escoamento da produção do território mato-grossense destinada à exportação, convergindo aos portos de Santos (SP) e Paranaguá (PR). Já a produção do território goiano segue, sobretudo, pela BR-153, BR-364 e a BR-050 etc., em direção ao porto de Santos. 
Essa alta concentração em apenas alguns portos ocasiona um dos entraves enfrentados pelo setor exportador no país, o que pode ser constatado no porto de Santos, com os congestionamentos de caminhões para ter acesso aos terminais e a insuficiência de locais para descarga e armazenamento. Tal problema é agravado quando as safras de soja batem recordes e sobrecarregam os pátios reguladores que já operam perto do limite, levando a formação de extensas filas de caminhões em Santos (SP), onde se encontra o maior complexo portuário da América Latina (EXAME, 2014).

Os gargalos (obstáculos operacionais) existentes na infraestrutura de transporte no Brasil, conforme Barat (2012, p. 20), "aumentam os custos de escoamento e reduz a competitividade das exportações". Esse autor ressalta que embora a evolução tecnológica tenha proporcionado desdobramentos no setor de transporte e comunicação, ampliando os fluxos de deslocamento de matéria-prima e produtos, com o surgimento de integrações entre modais (transporte multimodal), novas formas de acondicionamento, estocagem e distribuição, ainda há muitos obstáculos a serem superados na logística de exportação no Brasil.

Uma alternativa ao transporte de carne bovina no território brasileiro seria a ampliação do uso do modal ferroviário. Apesar da inflexibilidade de percurso, de acordo com Rodrigues (2011), esse modal é o mais viável economicamente para o transporte territorial de cargas em longas distâncias. Nas palavras desse autor: "um dos fatores de ganhos em competitividade é selecionar o modal de transporte que agregue menos custo ao produto durante o seu percurso" (RODRIGUES, 2011, p. 19). Portanto, a escolha de modais apropriados ao tipo de carga é essencial para a competitividade do negócio e o lucro dos produtores. Entretanto, para que a malha ferroviária sirva ao transporte de carnes é necessário o estabelecimento de novas parcerias entre os frigoríficos exportadores e as empresas detentoras do controle das ferrovias, visando à implantação de um maior número de vagões frigoríficos, especialmente, nas novas linhas férreas.

A partir do modal ferroviário, os estados brasileiros do Centro-Oeste poderiam destinar seus produtos para diferentes portos litorâneos, o que mitigaria o problema da concentração das exportações em apenas alguns portos. A título de exemplo, a Ferrovia Norte-Sul seria um novo corredor de exportação a favorecer o transporte de cargas em duas novas rotas de escoamento: uma passando por Goiás até o Pátio de Açailândia (MA), seguindo pela Estrada de Ferro Carajás até o porto do Itaqui, em São Luís (MA); e a outra rota de escoamento seria pelo porto de Belém (PA), dependendo ainda da concretização da ferrovia.

Os portos marítimos no Pará e Maranhão apresentam algumas vantagens em relação aos portos do Sul e Sudeste, dentre as quais podemos citar: a menor concentração de operações de transbordo, o que acaba por repercutir no tempo de espera para descarga e envio dos produtos; e menor distância geográfica em relação aos portos localizados em alguns dos principais países importadores de carne bovina do 
Brasil (TABELA 3). Essas vantagens comparativas contribuem para uma redução nos custos totais da logística de escoamento.

Tabela 03. Distância de portos brasileiros selecionados aos portos dos principais mercados estrangeiros, em milhas náuticas (nmi), e duração média da viagem marítima

\begin{tabular}{|c|c|c|c|c|c|c|c|c|c|}
\hline \multirow[b]{2}{*}{ PORTO } & \multicolumn{3}{|c|}{ Santos (São Paulo) } & \multicolumn{3}{|c|}{ Belém (Pará) } & \multicolumn{3}{|c|}{ Itaqui (Maranhão) } \\
\hline & $\begin{array}{l}\text { Distância } \\
\text { (nmi) }\end{array}$ & $\begin{array}{l}\text { Menor } \\
\text { Rota* }\end{array}$ & $\begin{array}{c}\text { Duração } \\
* *\end{array}$ & $\begin{array}{l}\text { Distância } \\
\text { (nmi) }\end{array}$ & $\begin{array}{l}\text { Menor } \\
\text { Rota* }\end{array}$ & $\begin{array}{c}\text { Duração } \\
* *\end{array}$ & $\begin{array}{l}\text { Distância } \\
\text { (nmi) }\end{array}$ & $\begin{array}{l}\text { Menor } \\
\text { Rota* }\end{array}$ & $\begin{array}{c}\text { Duração } \\
\text { ** }\end{array}$ \\
\hline $\begin{array}{l}\text { Hong Kong } \\
\text { (Hong Kong) }\end{array}$ & 10.274 & CBE & $28 \mathrm{~d} \mathrm{e} 13 \mathrm{~h}$ & 11.223 & CBE & $31 \mathrm{~d}$ e $04 \mathrm{~h}$ & 10.926 & $\mathrm{CBE}$ & $30 \mathrm{~d} \mathrm{e} 08 \mathrm{~h}$ \\
\hline $\begin{array}{l}\text { Tianjin } \\
\text { (China) }\end{array}$ & 11.581 & CBE & $32 \mathrm{~d} \mathrm{e} 04 \mathrm{~h}$ & 11.127 & $\mathrm{CP}$ & $30 \mathrm{~d}$ e $20 \mathrm{~h}$ & 11.288 & $\mathrm{CP}$ & $31 \mathrm{~d} \mathrm{e} 09 \mathrm{~h}$ \\
\hline $\begin{array}{l}\text { Alexandria } \\
\text { (Egito) }\end{array}$ & 6.175 & EG & $17 \mathrm{~d} \mathrm{e} 04 \mathrm{~h}$ & 5.098 & EG & $14 \mathrm{~d}$ e $04 \mathrm{~h}$ & 4.977 & EG & $13 \mathrm{~d}$ e $20 \mathrm{~h}$ \\
\hline $\begin{array}{l}\text { São Petersburgo } \\
\text { (Rússia) }\end{array}$ & 6.672 & $\mathrm{AO}$ & $18 \mathrm{~d} \mathrm{e} 13 \mathrm{~h}$ & 5.422 & $\mathrm{OA}$ & $15 \mathrm{~d}$ e $01 \mathrm{~h}$ & 5.350 & $\mathrm{OA}$ & $14 \mathrm{~d} \mathrm{e} 21 \mathrm{~h}$ \\
\hline $\begin{array}{l}\text { Bandar Abbas } \\
\text { (Irã) }\end{array}$ & 8.062 & CBE & $22 \mathrm{~d} \mathrm{e} 09 \mathrm{~h}$ & 8.055 & $\mathrm{CS}$ & $22 \mathrm{~d} \mathrm{e} 09 \mathrm{~h}$ & 7.934 & CS & $22 \mathrm{~d} \mathrm{e} 01 \mathrm{~h}$ \\
\hline $\begin{array}{c}\text { Los Angeles } \\
\text { (Estados Unidos) }\end{array}$ & 7.384 & $\mathrm{CP}$ & $20 \mathrm{~d} \mathrm{e} 12 \mathrm{~h}$ & 5.267 & $\mathrm{CP}$ & $14 d$ e $15 h$ & 5.428 & $\mathrm{CP}$ & $15 \mathrm{~d}$ e $02 \mathrm{~h}$ \\
\hline $\begin{array}{l}\text { Génova } \\
\text { (Itália) }\end{array}$ & 5.224 & EG & $14 \mathrm{~d} \mathrm{e} 12 \mathrm{~h}$ & 4.147 & EG & $11 \mathrm{~d}$ e $12 \mathrm{~h}$ & 4.026 & EG & $11 \mathrm{~d} \mathrm{e} 04 \mathrm{~h}$ \\
\hline $\begin{array}{l}\text { Roterdã } \\
\text { (Holanda) }\end{array}$ & 5.430 & $\mathrm{AO}$ & $15 \mathrm{~d} \mathrm{e} 02 \mathrm{~h}$ & 4.180 & OA & $11 \mathrm{~d}$ e $15 \mathrm{~h}$ & 4.108 & $\mathrm{OA}$ & $11 \mathrm{~d} \mathrm{e} 10 \mathrm{~h}$ \\
\hline
\end{tabular}

*. CBE - Cabo da Boa Esperança. CP - Canal do Panamá. CS - Canal de Suez. EG - Estreito de Gibraltar. OA - Oceano Attântico. **. Duração em dias e horas, com base na velocidade de 15 nós $=27,78 \mathrm{~km} / \mathrm{h}$. Fonte: SEA-DISTANCES.ORG (2017).

O porto de Tianjin (China), por exemplo, encontra-se a uma distância de 11.581 milhas náuticas (nmi) do porto de Santos, contornando o Cabo da Boa Esperança; já em relaçao ao porto de Belém, passando pelo Canal do Panamá, a distância reduz para $11.127 \mathrm{nmi}$, o que implica em um dia a menos de viagem (TABELA 03). No que se refere às exportações para o porto de Alexandria, no Egito, apresenta um menor percuso saindo pelo porto do Itaqui (MA); com uma redução de $1.198 \mathrm{nmi}$, em relação ao porto de Santos (SP).

O porto do Itaqui também se apresenta como uma boa opção, em relação ao percurso, quando as exportações se destinam para a Rússia (porto de São Petersburgo), Irã (porto de Bandar Abbas), Itália (porto de Génova) e Holanda (porto de Roterdã). Já o porto de Belém teria o menor percurso para os EUA. As exportações Belém-Los 
Angeles seriam de 2.117 mni a menos do que as exportações Santos-Los Angeles, o que reduz a viagem marítima em seis dias.

Desta forma, as exportações pelos portos do Norte e Nordeste brasileiro apresentam algumas vantagens significativas em relação aos portos do Sul e Sudeste, quando as cargas exportadas têm como destino alguns portos da Europa, do Oriente Médio e da América do Norte. Mas, em relação ao mercado de Hong Kong, o porto de Santos apresenta um menor percurso, tendo como rota o Cabo da Boa Esperança.

Em relação ao tipo de produto, a carne bovina in natura (Fresh Beef) está entre as principais commodities exportadas pelo país, em volume e valor arrecadado. Em 2016, os frigoríficos brasileiros exportaram 1.077.282 toneladas dessa commodity para 90 mercados estrangeiros, a um custo médio de US\$ 4.037/tonelada, o que resultou em um montante de 4,34 bilhões de dólares ou 78,8\% do total arrecadado com as exportações de carne bovina (ABIEC, 2016).

As remessas de carne industrializada foram de 105.573 toneladas no ano de 2016, o que permitiu a soma de US\$ 600 milhões na balança comercial brasileira, correspondendo a $10,9 \%$ do valor total das exportações de carne bovina. Em conjunto, os miúdos de bovino $(195.552 \mathrm{t})$, as tripas $(18.744 \mathrm{t})$ e as carnes salgadas $(3.283 \mathrm{t})$ resultaram em um montante de US\$ 565,7 milhões, participando em 10,3\% do valor arrecadado com os produtos derivados da carne bovina (ABIEC, 2016).

Ainda em 2016, conforme a Figura 5, os principais mercados de destino da carne bovina in natura brasileira foram o de Hong Kong, com a importação de 181.429 toneladas desta commodity ao custo de US\$ 718,8 milhões, China (165.619 t), Egito (164.930 t), Rússia (130.599 t) e Irã (94.964 t). Em relação à carne industrializada, segundo dados da ABIEC (2016), esse produto foi enviado para 98 mercados estrangeiros naquele ano, tendo como principais destinos os Estados Unidos, ao permitirem a entrada de 31.623 toneladas de carne bovina industrializada do Brasil, seguidos do Reino Unido (27.223 t), Bélgica (6.308 t), Holanda (4.649 t) e Itália (3.173 t).

Apesar de ser um importante parceiro comercial do Brasil para as exportações de carne bovina industrializada, de acordo com a Sociedade Nacional de Agricultura, os EUA impediam a entrada da carne bovina in natura brasileira em seu território até o acordo firmado em primeiro de agosto de 2016, quando o governo norte-americano permitiu o embarque desse produto para o seu território. A partir desse acordo, o Brasil conseguiu o aval de um dos países mais exigentes e rigorosos do mundo, o que significa um reconhecimento de suas boas condições sanitárias e um atestado de qualidade da carne (SNA, 2016). Ao longo daquele ano, o Brasil enviou 846 toneladas dessa commodity para o território estadunidense, no valor de 3,34 milhões de dólares (ABIEC, 2016). 


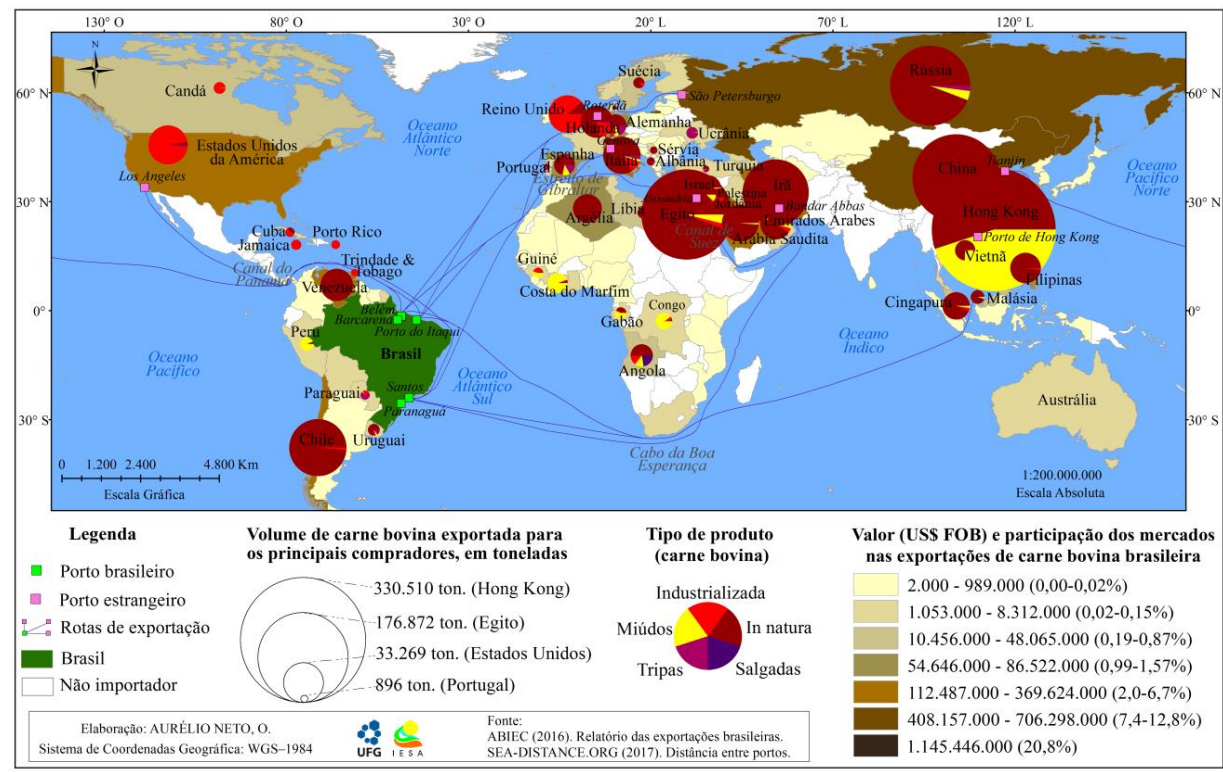

Figura 05. Mercados de destino da carne bovina brasileira, por valor e participação no faturamento, com o volume exportado para os principais compradores em 2016. Fonte: ABIEC (2016); SEA-DISTANCES.ORG (2017).

Como indica a Figura 5, os mercados estrangeiros que apresentam maior volume de importação de carne bovina brasileira, em 2016, independente do tipo de produto, foram os de Hong Kong (330. 510 t), Egito (176.872 t), China (165.754 t) e Rússia (138.785 t). Esses países foram os que mais contribuíram para o faturamento brasileiro nas exportações dessa commodity. Em conjunto, os países da União Europeia também se demonstram importantes parceiros comerciais do Brasil, em relação às exportações brasileiras de carne bovina, ao contribuírem com 13,4\% do valor arrecadado com as exportações dessa commodity em 2016.

Em relação à União Europeia, as remessas de carne bovina para a Itália somaram 30.642 toneladas, correspondendo a 3,5\% do valor faturado com esse produto; e a Holanda (Países Baixos) foi responsável por 3,3\% do valor exportado. Já a participação do Reino Unido no valor das exportações foi de $2,5 \%$, ao receber mais de 30 mil toneladas de carne bovina proveniente do território brasileiro. Destaca-se ainda a participação da Alemanha (1,3\%), ao somar 70,8 milhões de dólares na balança comercial brasileira, pelo recebimento de 10.058 toneladas de carne bovina (ABIEC, 2016).

Em 2016, o Brasil exportou carne bovina para 139 mercados estrangeiros. Apesar disso, os frigoríficos localizados no território brasileiro ainda encontraram restrições por parte de alguns países mais exigentes para comercializarem carne bovina, 
como é o caso do Japão. Além dos problemas de logísticas enfrentados pelos exportadores no Brasil, que configuram como barreiras operacionais, existem as barreiras tarifárias e as barreiras não tarifárias. Assim, estima-se que o volume de carne bovina exportada pelo Brasil poderia ser maior, caso não houvesse tantos obstáculos ao comércio internacional.

\section{Considerações finais}

A participação brasileira no mercado mundial de carne é relevante para o setor pecuário, o qual obtém maior viabilidade com as exportações. No cenário mundial, o Brasil se destaca entre os maiores produtores e exportadores de carne bovina, com preço menor que muitos concorrentes e capacidade de ofertar um produto com qualidade, dentro do padrão de sanidade animal exigido pelos principais mercados internacionais.

A pesquisa demonstrou que nos últimos anos houve uma redução no volume de abate de bovinos no território brasileiro, em resposta a retração do mercado doméstico. Contudo, o país se mantém entre os maiores produtores de carne bovina no mundo, com possibilidade técnica e geográfica de aumentar sua produção. Esse ganho na produtividade ocorreria a partir de um melhor aproveitamento das áreas de pastagens já existentes (atentando-se para as áreas subutilizadas e a recuperação de áreas de pastagens degradadas); incremento no abate de novilhos e novilhas que funcionam como uma reserva em pé, desde que a taxa de desfrute não comprometa a "renovação do rebanho"; e novos investimentos tecnológicos para um aumento da taxa de lotação no espaço rural e maior aproveitamento das carcaças.

Dentro do território brasileiro, o transporte de carnes é realizado, principalmente, por rodovias e portos e, em seguida, o produto é enviado por via marítima. Demonstra-se necessário reorientar a matriz de transporte para uma maior intermodalidade entre o modal rodoviário e ferroviário. Caberia ao modal rodoviário o transporte entre os frigoríficos e os pátios de transbordo da ferrovia, por ser o mais flexível, com maior disponibilidade de vias de acesso e rapidez na entrega. Por sua vez, o modal ferroviário seria adequado para o transporte de carga por longas distâncias, desde os pátios da ferrovia até os portos litorâneos.

Ainda em relação à logística de exportação da carne bovina, nota-se uma concentração em alguns portos da região Sul e Sudeste. Para diminuir essa concentração, a pesquisa sugere uma maior exportação pelos portos do Nordeste e Norte brasileiro, quando o produto tiver como destino os portos da Europa, do Oriente Médio e da América do Norte.

Por fim, a carne bovina brasileira apresenta qualidade e competitividade no mercado mundial, mas parece sofrer com a ganância de alguns indivíduos que visam o lucro acima da segurança alimentar. Nesse caso, cabe às instituições competentes 
investigar casos suspeitos; e ao governo informar a população interna e aos mercados estrangeiros dos problemas enfrentados, apontando soluções e mecanismos para evitar que eles se repitam. A transparência e as respostas rápidas, no sentido de apuração dos responsáveis e da correção de falhas encontradas, são as melhores formas de mitigar os efeitos de uma crise no setor de carne. Desta maneira, não caímos no mesmo erro cometido pelo governo argentino que, ao ocultar os problemas com o rebanho em 2001, desencadeou um descrédito a imagem do país que demorou a ser superado.

\section{Referências}

ABIEC. Associação Brasileira das Indústrias Exportadoras de Carne. Frigoríficos exportadores de carne bovina. 2017. Disponível em: <http://www.abiec.org.br/2_mapa.asp>. Acesso em: 09 jan. 2017.

ABIEC. Associação Brasileira das Indústrias Exportadoras de Carne. Perfil da pecuária no Brasil: relatório anual 2015. São Paulo: ABIEC, 2015.

ABIEC. Associação Brasileira das Indústrias Exportadoras de Carne. Relatório das Exportações Brasileiras de Carne Bovina: ano 2016. Disponível em: <http://www.abiec.com.br>. Acesso em: 30 mar. 17.

AGRI BENCHMARK. Beef and Sheep Report 2015: understanding agriculture worldwide. Disponível em: <http://www.agribenchmark.org>. Acesso em: 17 dez. 2016.

AGROIN. Média das exportações de carne cai 19\% depois de ação da PF. 2017. Disponível em: <http://www.agroin.com.br/noticias/8156/media-das-exportacoes-decarne-cai-19-depois-de-acao-da-pf >. Acesso em: 03 abr. 2017.

ALICEWEB. Sistema de Análise das Informações de Comércio Exterior. 2016. Disponível em: <http://aliceweb.mdic.gov.br/acesso>. Acesso em: 02 mar.2017.

BARAT, J. Gargalos e desenvolvimento. Revista Rumos: Economia e Desenvolvimento para os Novos Tempos, v. 36, n. 264, p. 20, 2012.

BECKER, B. K.; BERNARDES, J. A. Notas sobre a organização espacial da pecuária no Brasil. Anuário do Instituto de Geociência, v.2, p. 1-17, 1978.

BORGES, R. Governo celebra reabertura dos mercados de China, Egito e Chile à carne brasileira. El País, Espanha, 27 mar. 2017. Disponível em:

<http://brasil.elpais.com/brasil/2017/03/25/politica/1490449972_298516.html>. Acesso em: 03 abr. 2017.

BRASIL. Ministério da Indústria, Comércio Exterior e Serviços. Balança comercial do Brasil - 2016. Disponível em: <http://www.mdic.gov.br/balanca-comercial>. Acesso em: 20 mar. 2017. 
IBGE. Instituto Brasileiro de Geografia e Estatística. Pesquisa Pecuária Municipal 2015 (2000-2015). Disponível em:

<http://www2.sidra.ibge.gov.br/bda/tabela/listabl.asp?z=t\&o=24\&i=P\&c=3939>. Acesso em: 12 dez. 2016.

IBGE. Instituto Brasileiro de Geografia e Estatística. Pesquisa Trimestral de Abate dos Frigoríficos - 2016 (2000-2016). Disponível em:

<http://www2.sidra.ibge.gov.br/bda/tabela/protabl.asp?c=1092\&z=t\&o=1\&i=P>. Acesso em: 12 dez. /12/2016.

LUCENA, A. F. de; SOUZA, R. O. de. Comércio exterior em Goiás: uma análise empírica sobre a competitividade internacional das exportações dos complexos de soja e carne (1996-2008). In: LUCENA, A. F. de (Org.). Comércio exterior em Goiás: oportunidades e desafios. Goiânia: PUC Goiás, 2011. p. 193-216.

MARX, K. Contribuição à crítica da economia política. 2. ed. São Paulo: Expressão Popular, 2008. 288 p.

MATA, D. da; FREITAS, R. E. Exportações agropecuárias e características dos países importadores. In: DE NEGRI, João Alberto; ARAÚJO, Bruno César P. O. (Org.). As empresas brasileiras e o comércio internacional. Rio de Janeiro: IPEA, 2006. p. 371396.

NEVES, M. F. et al. Estratégias para a carne bovina no Brasil. São Paulo: Atlas, 2012. $272 \mathrm{p}$.

OECD. Food and Agriculture Organization of the United Nations OECD-FAO. Agricultural Outlook 2015-2024. Paris: OECD Publishing/Food and Agriculture Organization of the United Nations, 2015. 148 p. http://dx.doi.org/10.1787/agr_outlook-2015-en

OLIVO, N. Mercado mundial de carnes. 46. ed. Criciúma: Varela Editora, 2008.

ORDOÑEZ, H. et al. Caso PRINEX. Inovação e competitividade em gados e carnes. In: VILELLA, F.; NEVES, M. F.; SENESI, S.; PALAU, H. (Ed.). Agronegócios em Argentina e Brasil: uma estratégia conjunta e uma visão ao futuro. Buenos Aires: Ed. Faculdade de Agronomia, UBA, 2007. p. 1-82.

PARDI, M. C. et al. Ciência, higiene e tecnologia da carne. 2. ed. Goiânia: CEGRAFUFG, 2005.

REVISTA EXAME. Medidas contra filas em Santos esbarram em safra recorde. 2014. Disponível em: <http://exame.abril.com.br/economia/medidas-contra-filas-em-santosesbarram-em-safra-recorde-gargalos-e-desrespeito-2/>. Acesso em: 08 out. 2015.

RODRIGUES, P. R. A. Introdução aos sistemas de transporte no Brasil e à logística internacional. 4. ed. São Paulo: Aduaneiras, 2011. 246 p. 
SANTOS, M. Técnica, espaço, tempo: globalização e meio técnico-científico informacional. São Paulo: Hucitec, 1994. 190 p.

SCOT CONSULTORIA. Cotações: boi no mundo - 2016. Disponível em: <https://www.scotconsultoria.com.br/cotacoes/boi-no-mundo/>. Acesso em: 04 abr. 2017.

SEA-DISTANCES.ORG. Distância entre portos de exportação e importação. 2018. Disponível em: <http://www.sea-distances.org/>. Acesso em: 21 fev. 2017.

SNA. Sociedade Nacional de Agricultura. Brasil inicia embarques de carne bovina in natura para os Estados Unidos. 2016. Disponível em: <http://sna.agr.br/brasil-iniciaembarques-de-carne-bovina-in-natura-para-os-estados-unidos/>. Acesso em: $21 \mathrm{fev}$. 2017.

SOUZA, F. P. O mercado da carne bovina no Brasil. Rev. Acad. Ciênc. Agrár. Ambient., Curitiba, v. 6, n. 3, p. 427-434, jul./set. 2008.

USDA. United States Department of Agriculture. 2016. Disponível em: <https://apps.fas.usda.gov/psdonline/app/index.html\#/app/home>. Acesso em: $11 \mathrm{abr}$. 2017.

Onofre Aurélio Neto

Doutor em Geografia pela Universidade Federal de Goiás. Mestre e graduado em Geografia pelo Instituto de Estudos Socioambientais - IESA/UFG. Atualmente é professor efetivo da Secretaria Municipal de Educação e Esporte de Goiânia. Rua 226, 794, Setor Leste Universitário, CEP: 74610-130, Goiânia, Goiás. E-mail: opan.neto@yahoo.com.br 